\title{
Electrical signaling along the phloem and its physiological responses in the maize leaf
}

\author{
Jörg Fromm ${ }^{1 *}$, Mohammad-Reza Hajirezaei ${ }^{2}$, Verena K. Becker ${ }^{1}$ and Silke Lautner ${ }^{1}$ \\ ${ }^{1}$ Institute for Wood Biology, Universität Hamburg, Hamburg, Germany \\ ${ }^{2}$ Leibniz Institute of Plant Genetics and Crop Plant Research (IPK), Gatersleben, Germany
}

Edited by:

Aart Van Bel,

Justus-Liebig-University Giessen,

Germany

Reviewed by:

Jens B. Hafke,

Justus -Liebig-Universität, Germany

Eric Davies, North Carolina State

University, USA

\section{${ }^{*}$ Correspondence:}

Jörg Fromm, Institute for Wood

Biology, Universität Hamburg,

Leuschnerstrasse 91d, 21031

Hamburg, Germany

e-mail: joerg.fromm@

uni-hamburg.de
To elucidate the role of electrical signaling in the phloem of maize the tips of attached leaves were stimulated by chilling and wounding. Two different signals were detected in the phloem at the middle of the leaf using the aphid stylet technique: (1) action potentials (AP) arose in the phloem after chilling; and (2) variation potentials (VPs) were evoked after wounding the leaf tip. Combined electric potential and gas exchange measurements showed that while the wound-induced VP moved rapidly towards the middle of the leaf to induce a reduction in both the net- $\mathrm{CO}_{2}$ uptake rate and the stomatal conductance, there was no response in the gas exchange to the cold-induced AP. To determine if electrical signaling had any impact on assimilate transport the middle of the leaf was exposed to ${ }^{14} \mathrm{CO}_{2}$. Autoradiography of labeled assimilates provided evidence that phloem and intercellular transport of assimilates from mesophyll to bundle sheath cells was strongly reduced while the cold-induced AP moved through. In contrast, wound-induced VP did not inhibit assimilate translocation but did reduce the amount of the labeled assimilate in phloem and bundle sheath cells. Biochemical analysis revealed that callose content increased significantly in chilled leaves while starch increased in chilled but decreased in wounded leaves. The results led to the conclusion that different stimulation types incite characteristic phloem-transmitted electrical signals, each with a specific influence on gas exchange and assimilate transport.

Keywords: action potential, assimilate translocation, callose, gas exchange, phloem, plasmodesmata, variation potential

\section{INTRODUCTION}

In recent decades it has become clear that the phloem not only enables the bulk flow of assimilates but also transmits various chemical and electrical signals. Since sieve elements and their companion cells are more or less symplastically isolated from neighboring cells and contain a saline luminal fluid $(80-100 \mathrm{mM}$ $\mathrm{K}^{+}$), they represent a low-resistance channel for electrical conductance and signal transmission along the plasma membrane. It has been suggested that electrical signals play a major role in inter- and intracellular communication and in the regulation of physiological processes at both the molecular and organism level (Davies, 1987). These signals can be evoked by various stimuli, such as wounding (e.g., by chewing insects), cold-shock, heating, light-pulses or touch, and they are responsible for rapid transmission of information within the plant body in order to enable a response of distant organs to (e.g.) dangerous events. Two main types of electrical signals in plants have been identified: action potentials (APs), evoked by non-damaging stimuli, and variation potentials (VPs), triggered by mechanical damage or heating. APs are less long lasting and travel faster than VPs and are mainly transmitted along the phloem, while VPs depend on a rapid loss of tension in the xylem vessels and can travel towards the phloem to be propagated over long distances.

These two types of electrical signals are related to numerous physiological effects in plants. Insectivorous plants, for example, such as Drosera and Dionaea, use electrical signals within leaf traps as a means of catching insects in order to secure their nitrogen supply (Williams and Pickard, 1972; Hedrich, 2012). The mechanism of Dionaea trap closing was investigated in detail during the last years by Forterre et al. (2005) and Volkov et al. (2008), indicating that the release of elastic energy stored in the trap leaves plays a main role in the rapid closing of the trap. In Mimosa, meanwhile, electrical signals cause the leaflets to move, making the leaf appear unappealing to a would-be herbivore. In addition, recent studies have shown that heat-induced electrical signals cause a strong local, as well as a systemic, reduction in net $\mathrm{CO}_{2}$ uptake and the quantum yield of electron transport in Mimosa (Koziolek et al., 2004), poplar (Lautner et al., 2005) and maize (Grams et al., 2009).

Recently, strong evidence has been presented for a relationship between electrical long-distance signaling, $\mathrm{Ca}^{2+}$ influx, and cellular responses to this influx, including sieve-tube conductivity and mass flow (Van Bel et al., 2011). In the phloem of Populus trichocarpa the spread of a heat-induced signal depends on the availability of calcium (Lautner et al., 2005) and $\mathrm{Ca}^{2+}$ influx is suggested to be the key link between electrical signals and the resultant chemical responses. In maize, meanwhile, the amount of cytoplasmic calcium has been found to increase during propagation of APs evoked by cold-shock (Fromm and Bauer, 1994). Since a reduction of phloem 
transport was observed during electrical signaling in this earlier study of maize, the aim of the present study was to clarify the impact of phloem-transmitted electrical signals (APs and VPs) on assimilate transport and distribution within the maize leaf.

\section{MATERIALS AND METHODS PLANT MATERIALS}

Maize plants (Zea mays L.) were grown from seeds in pots in climate chambers under a light intensity of $400 \mu \mathrm{mol} \mathrm{m} \mathrm{m}^{-2} \mathrm{~s}^{-1}$ provided by mercury halide lamps and a $14 \mathrm{~h}$ light $/ 10 \mathrm{~h}$ dark period. The temperature was $24-25^{\circ} \mathrm{C}$ and relative humidity was $70 \%$. Measurements were performed on mature leaves on plants between 80 and $120 \mathrm{~cm}$ in height.

\section{PLANT STIMULATION AND SAMPLING}

While one control plant remained untreated a tip of a mature leaf of a second plant was cold-stimulated by ice water $\left(4^{\circ} \mathrm{C}\right)$ and a leaf tip of a third plant was wounded by cutting. Electric potential recordings were made during stimulation at $8-10 \mathrm{~cm}$ distance from the stimulation site. For biochemical analysis the leaf tip was stimulated once per min and the middle part of the leaf was harvested in liquid nitrogen after a $15 \mathrm{~min}$ stimulation period. For autoradiography leaf tips were also stimulated once per min and leaves were harvested after a $15 \mathrm{~min}$ as well as a $30 \mathrm{~min}$ stimulation period.

\section{ELECTRIC POTENTIAL RECORDINGS}

A mature maize leaf was excised from a plant and the cut crosssection of the leaf was submerged into a cuvette with artificial pond water (composed of $1.0 \mathrm{mM} \mathrm{NaCl}, 0.1 \mathrm{mM} \mathrm{KCl}, 0.1 \mathrm{mM}$ $\mathrm{CaCl}_{2}$ and $1.0 \mathrm{mM}$ MES, adjusted with Tris to $\mathrm{pH}$ 6.0) into which a reference electrode was also immersed. The leaf was placed inside a Faraday cage and aphids (Rhopalosiphum padi) were allowed to settle overnight on the lower side. On the following day one aphid was cut from its stylet by using a laser beam generator (Beck, Neu-Isenburg, Germany) connected to a Zeiss microscope. By using a micromanipulator the exudate at the stylet stump was then brought into contact with the tip of a microelectrode filled with $100 \mathrm{mM} \mathrm{KCl}$. The microelectrode was connected to a preamplifier with an input impedance of $>10^{12} \mathrm{ohms}$, to which an amplifier (Model 750, WPI, USA) was attached. Prior to each experiment, the microelectrode was calibrated by dipping it into a trough with artificial pond water, which was connected electrically with the reference electrode in the cuvette by an agar bridge. After connecting the microelectrode to the stylet stump, the resting potential of the sieve element was established and the tip of the leaf was stimulated at $8-10 \mathrm{~cm}$ distance from the site of the microelectrode. Action potentials were evoked by ice water $\left(4^{\circ} \mathrm{C}\right)$ while VPs were generated by wounding (cutting) the leaf tip.

\section{LEAF GAS EXCHANGE MEASUREMENTS}

Assessment of leaf gas exchange was performed using a Waltz CQP-130 porometer (Effeltrich, Germany). Measuring conditions were $250 \mu \mathrm{mol} \mathrm{m} \mathrm{m}^{-2} \mathrm{~s}^{-1}$ light intensity, a leaf temperature of $25^{\circ} \mathrm{C}$, and $60 \%$ relative air humidity.

\section{AUTORADIOGRAPHY}

For macroautoradiographic demonstration of phloem transport the middle of different treated leaves was exposed to 2.9 Mbq ${ }^{14} \mathrm{CO}_{2}$. After 15 as well as $30 \mathrm{~min}$ all leaves were quickly frozen in dry-ice, freeze-dried and exposed on X-ray film. Microautoradiographs were made from the ${ }^{14} \mathrm{CO}_{2}$ exposed blades inside plexiglas boxes at the middle of the leaves after $15 \mathrm{~min}$ exposure. Small sections of the leaves (1-3 $\mathrm{mm}$ in diameter) were quickly frozen in isopentane which was pre-cooled with liquid nitrogen. After freeze drying and embedding in Spurr's resin medium (Spurr, 1969) sections were cut with a Reichert Ultracut E microtome and fixed with $0.1 \mathrm{~N} \mathrm{NaOH}$ and $5 \% \mathrm{H}_{5} \mathrm{IO}_{6}$, which later improved the staining with $0.05 \%$ toluidine blue, $\mathrm{pH}$ 7.0. The sections were coated with liquefied photoemulsion (Ilford L4), exposed for 6 weeks and developed in a Kodak D-19 developer.

\section{BIOCHEMICAL ANALYSIS}

After the different treated leaves were quickly frozen in liquid nitrogen, phosphorylated intermediates were measured according to Hajirezaei et al. (2006). ATP was assayed in $100 \mathrm{mM}$ Tris- $\mathrm{HCl}$ ( $\mathrm{pH} 8.1$ ), $0.25 \mathrm{mM} \mathrm{NADP}{ }^{+}, 0.85 \mathrm{mM}$ Glc, 0.56 units of Glc-6-P dehydrogenase, and 0.7 units of phosphoglucose isomerase. 0.6 units of hexokinase were added to start the reaction. Other glycolytic intermediates and soluble carbohydrates were analysed as described by Stitt et al. (1989).

Starch measurement was carried out essentially as described by Ahkami et al. (2009). The sediment from the extraction was washed two times in $0.5 \mathrm{ml}$ of ethanol and suspended in $0.8 \mathrm{ml}$ of $0.2 \mathrm{M} \mathrm{KOH}$. After incubation for $1 \mathrm{~h}$ at $95^{\circ} \mathrm{C}$, the suspension was neutralized by $0.14 \mathrm{ml}$ of acetic acid and centrifuged. Then, $45 \mu \mathrm{l}$ of amyloglucosidase buffer was added to $5 \mu \mathrm{l}$ of the suspension, which was incubated overnight at $37^{\circ} \mathrm{C}$. The produced glucose was assayed photometrically.

Callose was measured according to the method described by Koehle et al. (1985) with some modifications. In particular, $50 \mathrm{mg}$ fresh tissue was frozen after the treatment and homogenized using a mill (Retsch MM400, Germany) for $1 \mathrm{~min}$ in frozen state. The homogenate was mixed with $500 \mu \mathrm{l} 1 \mathrm{~N} \mathrm{NaOH}$ and incubated for $15 \mathrm{~min}$ at $80^{\circ} \mathrm{C}$ while shaking at $100 \mathrm{rpm}$. Subsequently the homogenate was centrifuged at 14,000 rpm (425 g). $200 \mu \mathrm{l}$ of the supernatant was mixed with $400 \mu \mathrm{l} 0.1 \%$ aniline blue (SigmaAldrich, Germany) giving a red-violet colour. As blank $200 \mu \mathrm{l}$ $\mathrm{NaOH}$ was used instead of sample. Thereafter, $210 \mu \mathrm{l}$ of $1 \mathrm{~N} \mathrm{HCl}$ was added to all samples (colour turns to deep blue). The $\mathrm{pH}$ of all samples was adjusted by the addition of $590 \mu \mathrm{l}$ of a mixture of $1 \mathrm{M}$ glycine and $1 \mathrm{M} \mathrm{NaOH}$. All samples were incubated then for $20 \mathrm{~min}$ at $50^{\circ} \mathrm{C}$ and allowed thereafter to stand for $30 \mathrm{~min}$ at room temperature (colour disappears). The measurement was carried out immediately after incubation using a fluorometer infinite M200 (Tecan, Germany) with an excitation wavelength at $400 \mathrm{~nm}$ and an emission wavelength at $510 \mathrm{~nm}$.

\section{RESULTS ELECTRICAL SIGNALING}

After a microelectrode was brought into contact with a cut aphid stylet, a resting potential of the sieve elements in the range 
of -141 to $-157 \mathrm{mV}(n=5)$ could be detected. This resting potential was similar to the sieve tube potential of Mimosa pudica (Fromm, 1991). Subsequently, when the leaf tip was stimulated by water ice at a distance of $10 \mathrm{~cm}$, an action potential with an amplitude of more than $70 \mathrm{mV}$ and a speed of $3 \mathrm{~cm} \mathrm{~s}^{-1}$ was released (Figure 1A). For comparison, when the leaf tip was wounded by cutting, a VP with a short transient depolarization followed by a longer hyperpolarization, and a speed of $0.5 \mathrm{~cm}$ $\mathrm{s}^{-1}$, was detected in the phloem (Figure 1B). Regarding refractory periods, it was found that it was not possible to generate a second signal for $50 \mathrm{~s}$ after the first had occurred. We could detect further signals when the leaf was stimulated once per minute, however.

\section{RESPONSE OF GAS EXCHANGE TO ELECTRICAL SIGNALING}

The gas exchange was measured at the middle of the leaf while the tip was being stimulated at a distance of $10 \mathrm{~cm}$. Whereas cooling had no effect on both the $\mathrm{CO}_{2}$ assimilation and transpiration rates, wounding led to a clear reduction in both parameters (Figure 2). The transpiration rate began to decrease as soon as $6 \mathrm{~min}$ after wounding, indicating that wounding the leaf tip causes stomatal closure in the rest of the leaf. Simultaneously, a significant reduction in the assimilation rate was detected.

\section{RESPONSE OF ASSIMILATE TRANSLOCATION TO ELECTRICAL SIGNALING}

Plants identical in height and age were predarkened for $48 \mathrm{~h}$ before the middle part of mature attached leaves was exposed to ${ }^{14} \mathrm{CO}_{2}$ for $30 \mathrm{~min}$. During this period one plant remained unstimulated while the leaf tip of a second plant was cold-stimulated $\left(4^{\circ} \mathrm{C}\right)$ once per minute and the tip of a third plant was

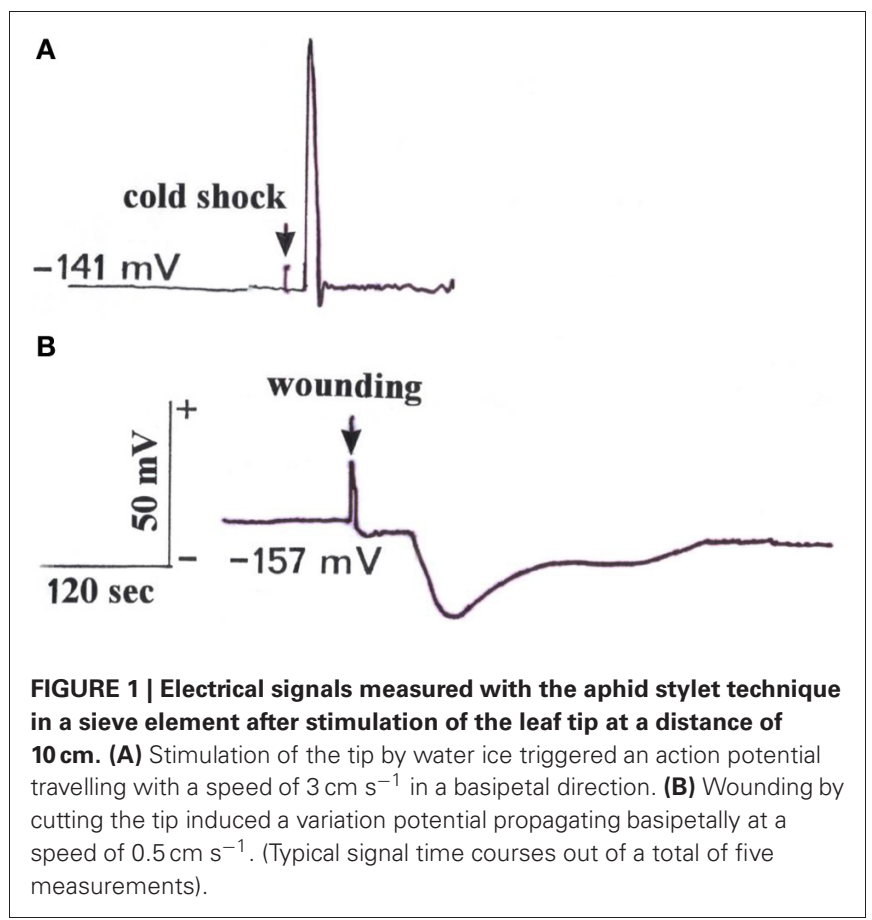

wounded once per minute. Macroautoradiography showed that in untreated (Figure 3A) and wounded leaves (Figure 3C) the ${ }^{14} \mathrm{C}$-labeled photoassimilates extended in the expected normal distribution from the exposed middle area (black) towards the leaf base. In contrast, in cold-shocked leaves phloem transport decreased significantly in all veins of the leaf (Figure 3B), as has previously been shown by Fromm and Bauer (1994). In another set of experiments plants were exposed to ${ }^{14} \mathrm{CO}_{2}$ only for $15 \mathrm{~min}$. Macroautoradiographs of such leaves showed that phloem transport did not extend into the non-exposed leaf base, either in unstimulated nor in stimulated plants (Figure 4).

To check for physiological causes for the reduction of phloem transport, microautoradiographs were made of the leaf areas exposed to ${ }^{14} \mathrm{CO}_{2}$. After a $30 \mathrm{~min}$ exposure period the tissue was heavily labeled (not shown), therefore microautoradiographs were made from leaves exposed to ${ }^{14} \mathrm{CO}_{2}$ after $15 \mathrm{~min}$. The results are shown in Figure 5, and reveal that in unstimulated leaves (Figure 5A) label accumulated massively in bundle-sheath cells (B) of all veins, while the mesophyll (M) was only slightly labeled. In comparison to unstimulated leaves, the microautoradiographs of cold-stimulated leaves revealed that the translocation of ${ }^{14} \mathrm{C}$-assimilates from mesophyll to bundle-sheath cells was significantly reduced (Figure 5B). Here, label appeared to be more concentrated in the outer walls of the bundle-sheath (arrows) than inside these cells. Clearly, therefore, cold-induced action potentials yielded distinct inhibition of intracellular transport in the maize leaf. The ${ }^{14} \mathrm{CO}_{2}$ exposed areas of wounded leaves, meanwhile, showing some label slightly accumulating at the bundle sheath cell wall but that most of the label was distributed more or less equally in all cells of the leaves (Figure 5C).

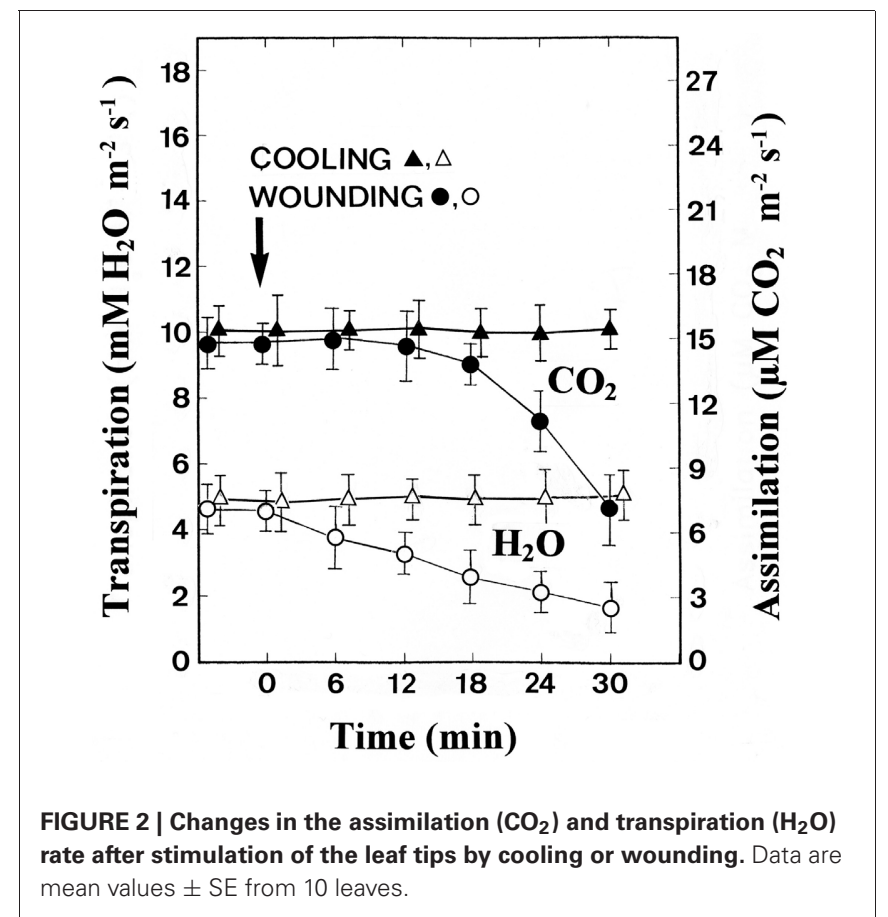




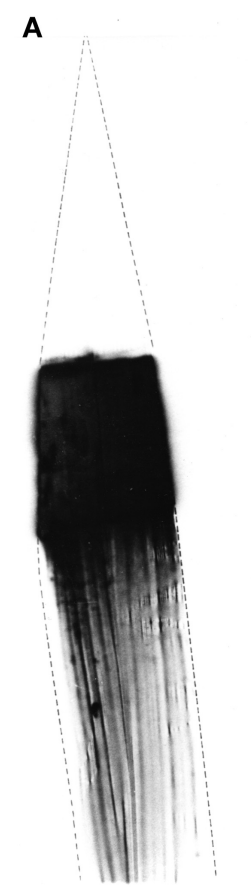

B

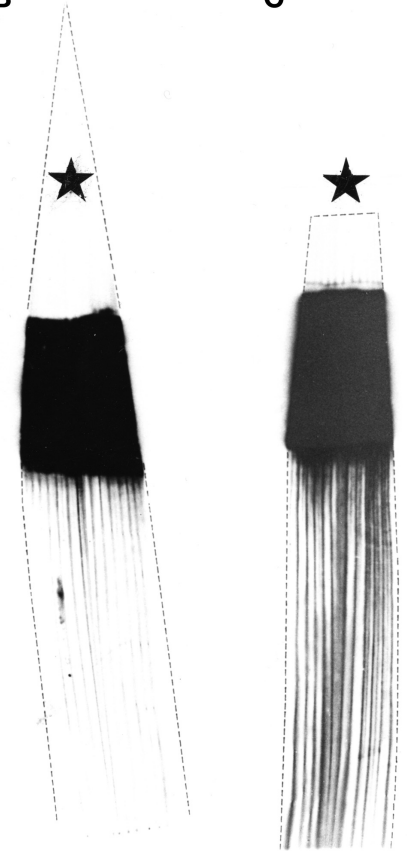

FIGURE 3 | Macroautoradiographs of three maize leaves which were labeled with ${ }^{14} \mathrm{CO}_{2}$ for $30 \mathrm{~min}$ in the middle section. Labeled assimilates were exported in a basipetal direction. (A) The left leaf remained unstimulated, (B) the middle leaf was cold-shocked at the tip (starlet) and (C) the right leaf was wounded at its tip (starlet) once per min.

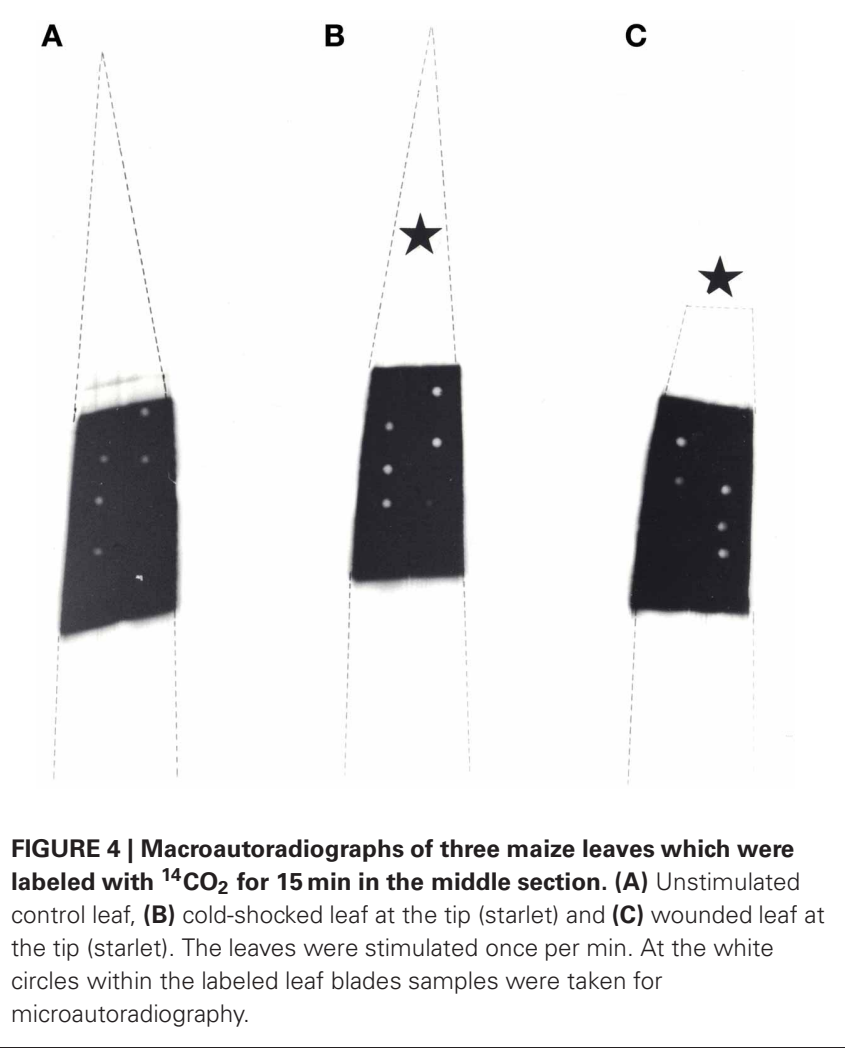

\section{BIOCHEMICAL RESPONSES}

To check if the different patterns of labeling are related to changes in the photosynthetic metabolism, the concentrations of various metabolites in the ${ }^{14} \mathrm{CO}_{2}$ exposed areas were measured photometrically after a stimulation period of $15 \mathrm{~min}$. In Table 1 it is shown that, compared to unstimulated leaves, cold-shocked leaves had higher malate, PEP, PGA, TrioseP and ATP, while starch levels increased more than two-fold. Wounded leaves, in contrast, exhibited lower levels of almost all investigated metabolites. The dramatic increase of starch within the chloroplasts of the coldshocked leaves reflects the elimination of photosynthate transport via plasmodesmata, while starch in the wounded leaves decreased clearly in correlation to the reduction in $\mathrm{CO}_{2}$ uptake (Figure 2).

Callose is well known as a substance which serves to plug plasmodesmata and occlude sieve-plate pores. Measurements showed
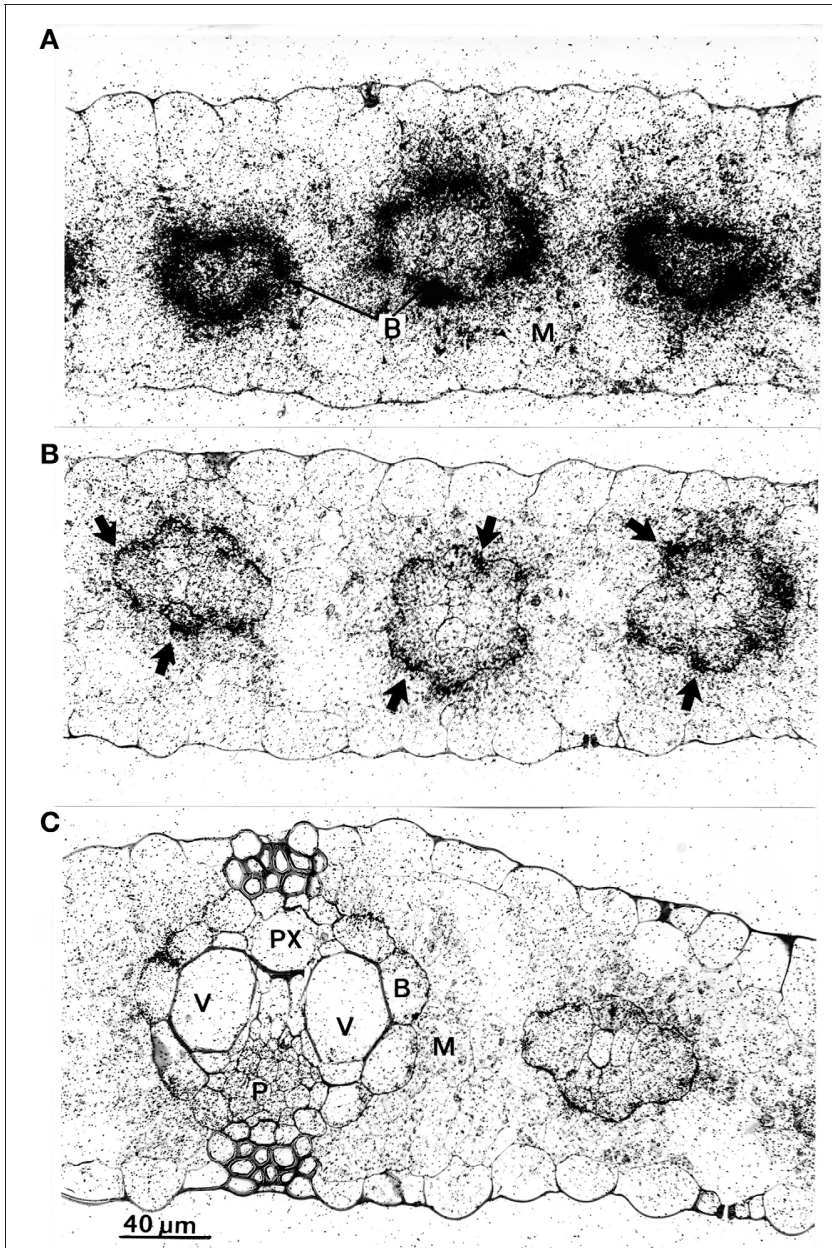

FIGURE 5 | Microautoradiographs of leaf areas which were exposed to ${ }^{14} \mathrm{CO}_{2}$. (A) In the unstimulated leaf, label is concentrated in bundle sheath cells (B). (B) In leaves which were cold-shocked at their tips label concentrated at the cell walls between mesophyll (M) and bundle sheath cells (arrows). (C) In tip-wounded leaves label was more or less distributed equally in all living cells. There was a slight accumulation, however, at the mesophyll/bundle sheath cell wall. P, phloem; PX, protoxylem; V, vessel. 
that in cold-shocked leaves callose concentrations increased significantly compared to the unstimulated control leaves (Figure 6). Obviously, the movement of photoassimilates from the mesophyll cells to the bundle sheath cells would be inhibited by closed plasmodesmata in cold-stimulated leaves.

\section{DISCUSSION}

Previous studies on electrical signaling in maize have shown that chilling leaf tips generates action potentials with amplitudes of more than $50 \mathrm{mV}$ which are transmitted basipetally in sieve tubes (Fromm and Bauer, 1994). They were measured via severed aphid stylets, as first described for the membrane potential by Wright and Fisher (1981). APs are known to be generated by potassium, chloride and calcium fluxes, and to reduce phloem transport in

\begin{tabular}{|c|c|c|c|}
\hline Metabolite & $\begin{array}{l}\text { Content in } \\
\text { unstimulated } \\
\text { leaves }\end{array}$ & $\begin{array}{l}\text { Content in } \\
\text { cold-shocked leaves } \\
{\left[\mu \mathrm{mol} \mathrm{g} \mathbf{g}^{-1} \text { fresh wt] }\right.}\end{array}$ & $\begin{array}{l}\text { Content in } \\
\text { wounded } \\
\text { leaves }\end{array}$ \\
\hline Malate & $2.10 \pm 0.25$ & $2.89 \pm 0.18^{*}$ & $1.70 \pm 0.45$ \\
\hline PEP & $0.35 \pm 0.05$ & $0.38 \pm 0.17$ & $0.27 \pm 0.13$ \\
\hline Pyruvate & $0.54 \pm 0.29$ & $0.45 \pm 0.15$ & $0.29 \pm 0.11$ \\
\hline PGA & $1.52 \pm 0.38$ & $1.61 \pm 0.50$ & $0.94 \pm 0.16$ \\
\hline DHAP & $0.68 \pm 0.12$ & $1.10 \pm 0.17^{*}$ & $0.32 \pm 0.13^{*}$ \\
\hline GAP & $0.04 \pm 0.01$ & $0.24 \pm 0.05^{*}$ & $0.13 \pm 0.01 *$ \\
\hline Sucrose & $0.99 \pm 0.18$ & $0.86 \pm 0.10$ & $1.35 \pm 0.21$ \\
\hline Glucose & $0.20 \pm 0.07$ & $0.18 \pm 0.05$ & $0.17 \pm 0.09$ \\
\hline Fructose & $0.08 \pm 0.01$ & $0.08 \pm 0.01$ & $0.08 \pm 0.02$ \\
\hline ATP & $0.13 \pm 0.02$ & $0.17 \pm 0.05$ & $0.11 \pm 0.04$ \\
\hline Starch & $1564 \pm 398$ & $3640 \pm 1050 *$ & $1040 \pm 86$ \\
\hline
\end{tabular}

(Asterisks indicate significant differences to control- $P=0.05-$, calculated by student's t-test). The photometrically measured data show that cold-shocked leaves have higher malate, PEP, PGA, TrioseP, ATP and starch levels than untreated leaves, whereas wounded leaves have lower levels of almost all metabolites.

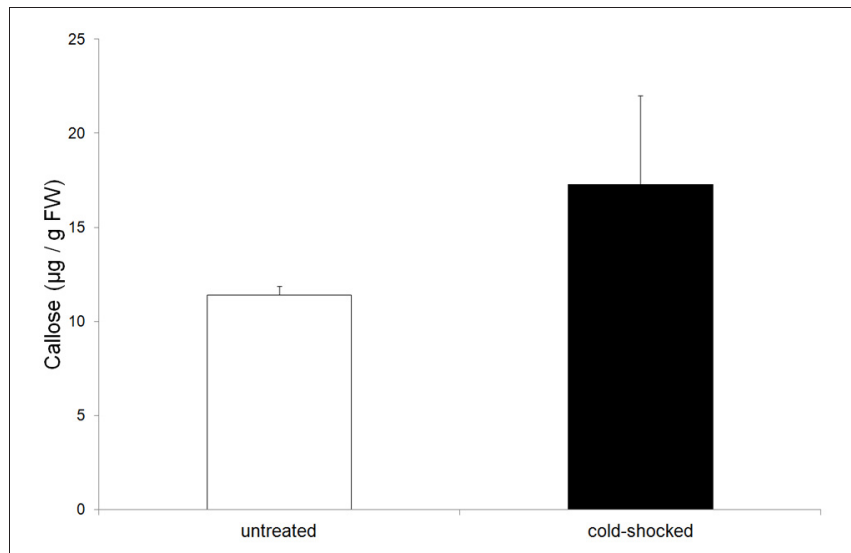

FIGURE 6 | Concentration of callose in untreated and cold-shocked leaves ( $n=4 \pm S D$ ). Callose increased significantly in cold-shocked leaves. maize. In addition to cold-shock induced action potentials, reirrigation of drought-stressed maize plants also induce action potentials, travelling via the phloem from roots to leaves in order to regulate photosynthesis (Grams et al., 2007). Apart from cold and watering stimuli, heat stimulation also evokes electrical signals in maize that travel through the leaf while reducing the net $\mathrm{CO}_{2}$ uptake rate and the photochemical quantum yield of both photosystems I and II (Grams et al., 2009).

The controlling factors in the reduction of phloem transport caused by cold-induced action potentials are so far not clear, however. On the one hand, it is well known that chilling localized areas of the transport path inhibits phloem transport in many plant species, due to a mechanical blockage of sieve plate pores or to a change in the hydrostatic pressure and osmolarity of the sieve sap. Additionally, abrupt drops in temperature are also known to cause an interruption of assimilate transport in plants (Pickard et al., 1978; Minchin and Thorpe, 1983). The fact that coldinduced action potentials also inhibit phloem transport distant from the stimulation site, and the mechanisms through which this is achieved still need to be clarified, however, and was one aim of the present study. In this regard, callose is well known as a substance that serves to plug plasmodesmata and occlude sieveplate pores. In regard to sieve-plate occlusion there is evidence that this is a dual process involving protein in tandem with callose, since sieve elements have been observed to occlude quicker by proteins than by callose production (Furch et al., 2007, 2010). In Vicia faba, dependent on a rise in calcium concentration, protein bodies, so-called forisomes (Knoblauch et al., 2001), disperse abruptly coincident with the propagation of an electrical signal (Furch et al., 2007). In intact Cucurbita maxima plants, however, a different mechanism for occlusion has been found: sieve element proteins coagulate several centimeters away from the stimulation site, while several minutes after stimulation callose deposition reached its maximum (Furch et al., 2010). Such a dual occlusion process guarantees very rapid and effective sieve tube sealing after damage and should prevent sap loss from sieve tubes.

In the present study, microautoradiographs from the ${ }^{14} \mathrm{CO}_{2}$ exposed leaf areas showed that label accumulated at the outer walls of bundle sheath cells upon cold stimulation (Figure 5B). Furthermore, the levels of malate, PEP, TrioseP and ATP increased. These metabolites occur primarily in the mesophyll of maize leaves and their increase indicates that photosynthate transport via plasmodesmata is interrupted. This conclusion is confirmed by two other observations:

(a) the movement of photosynthetic intermediates between mesophyll and sheath cells is restricted to the plasmodesmata (Evert et al., 1977) and;

(b) a clear increase in the callose level in cold-shocked leaves (Figure 6).

The increase in callose level is most likely to be responsible for occluded plasmodesmata and thus an interruption in the intracellular transport of photosynthetic intermediates which might also lead to a reduction of the phloem loading process. Furthermore, electrical signaling via plasmodesmata is a well-known phenomenon (Van Bel and Ehlers, 2005) and 
plasmodesmata provide a route for the passage of electric current between cells (Spanswick and Costerton, 1967; Spanswick, 1972). The macroautoradiographic demonstration of reduced phloem transport in cold-shocked leaves (Figure 3B), therefore, might be caused by a decrease of phloem loading as well as by callose-occluded sieve-plate pores. A possible link between electrical signaling and callose biosynthesis might be the calciuminduced activation of callose synthase. Since action potentials are known to be based on an initial influx of calcium (Kikuyama and Tazawa, 1983; Beilby, 1984) an increase in cytoplasmic calcium during electrical signaling might also serve to activate callose synthase. Apart from callose, starch also increased significantly in cold-shocked leaves (Table 1), probably due to the interruption of assimilate transport and the fact that the $\mathrm{CO}_{2}$-uptake rate does not respond to cold-induced action potentials (Figure 2).

In contrast to chilled leaves, tip-wounded leaves exhibited a decrease in both $\mathrm{CO}_{2}$ uptake and transpiration rate (Figure 2). The transpiration rate began to decrease as soon as $6 \mathrm{~min}$ after wounding and was followed by a significant reduction in the assimilation rate. These observations are in close agreement with the reduction of label in the cells of the ${ }^{14} \mathrm{CO}_{2}$ exposed leaf areas (Figure 5C) and indicate that wounding the leaf tip causes stomatal closure and photosynthetic decline in the middle of the leaf. Consequently, starch content decreased in wounded leaves in comparison to the unstimulated control leaves (Table 1). When the leaf tip is wounded, the water status of the whole leaf changes and thus xylem tension is lost. The resulting hydraulic wave can be transduced into ion flux changes through mechanosensory channels in the neighboring living cells (Stankovic et al., 1998; Davies and Stankovic, 2006) to generate a VP which moves laterally via the plasmodesmata into the phloem from where it can be

\section{REFERENCES}

Ahkami, A. H., Lischewski, S., Haensch, K. T., Porfirova, S., Hofmann, J., Rolletschek, H., et al. (2009). Molecular physiology of adventitious root formation in Petunia hybrida cuttings: involvement of wound response and primary metabolism. New Phytol. 181, 613-625, doi: 10.1111/j.1469-8137. 2008.02704.x

Beilby, M. J. (1984). Calcium and plant action potentials. Plant Cell Environ. 7, 415-421. doi: 10.1111/j.13653040.1984.tb01431.x

Davies, E. (1987). Action potentials as multifunctional signals in plants: a unifying hypothesis to explain apparently disparate wound responses. Plant Cell Environ. 10, 623-631. doi: 10.1111/j.13653040.1987.tb01844.x

Davies, E., Zawadzki, T., and Witters, D. (1991). "Electrical activity and signal transmission in plants: how do plants know?" in Plant Signalling, Plasma Membrane and Change of State, eds C. Penel and H. Greppin,
(Geneva: University of Geneva), 119-137.

Davies, E., and Stankovic, B. (2006). "Electrical signals, the cytoskeleton, and gene expression: a hypothesis on the coherence of the cellular responses to environmental insult," in Communication in Plants Neuronal Aspects of Plant Life, eds F. Baluska, S. Mancuso, and D. Volkmann (Berlin Heidelberg: W. (1977). Distribution and structure of the plasmodesmata in mesophyll and bundle-sheath cells of Zea mays L. Planta 136, 77-89. doi: 10.1007/BF00387929

Forterre, Y., Skothelm, J. M., Dumals, J., and Mahadevan, L. (2005). How the venus flytrap snaps. Nature 433, 421-425. doi: 10.1038/nature03185

Fromm, J. (1991). Control of phloem unloading by action potentials in Mimosa. Physiol. Plant. 83, 529-533. doi: 10.1111/j.13993054.1991.tb00130.x

Fromm, J., and Bauer, T. (1994). Action potentials in maize sieve Springer Verlag), 309-320.

Evert, R. F., Eschrich, W., and Heyser,

propagated over long distances (Figure 1B). VPs (also called slow wave potentials because of their slow repolarization phase) are therefore a likely candidate for transmitting the wounding stimulus and have been extensively studied in numerous plant species such as cucumber and pea seedlings (Stahlberg and Cosgrove, 1992, 1994). Regarding the ionic mechanism, VPs usually are initiated by mechanosensitive $\mathrm{Ca}^{2+}$ channels and also involve a transient shutdown of a P-type $\mathrm{H}^{+}$-ATPase in the plasma membrane (Stahlberg et al., 2006). However, in maize wounding by cutting triggered a VP with a short transient depolarization followed by a long-lasting hyperpolarization (Figure 1B). The short depolarization exhibits AP-like kinetics which also has been reported after repeated flaming of sunflower leaves (Davies et al., 1991; Stahlberg et al., 2006). Since it is unlikely that the hyperpolarization is caused by a shutdown of the proton pump, in future experiments other ionic fluxes are needed to explain signals of the negative sign, such as $\mathrm{K}^{+}$-efflux or an activation of the proton pump.

In conclusion, in a previous study (Fromm and Bauer, 1994) we provide evidence that cold-shock induced action potentials spread via the phloem through the leaf, and upon signal transmission, phloem transport is reduced. In the present study a range of evidence is given that an increasing callose level occludes the plasmodesmata between mesophyll and bundle sheath cells. As a consequence, phloem loading is reduced and metabolite levels increase within the mesophyll. In a similar way, wound-induced VPs also travel via the phloem, however, in contrast to action potentials, they lead to a reduction in photosynthesis and callose content. Future studies will be directed towards a better understanding of the relationship between electrical signals and physiological responses within the veins.

tubes change phloem translocation. J. Exp. Bot. 45, 463-469. doi: 10.1093/jxb/45.4.463

Furch, A. C. U., Hafke, J. B., Schulz, A., and van Bel, A. J. E. (2007). $\mathrm{Ca}^{2+}$-mediated remote control of reversible sieve tube occlusion in Vicia faba. J. Exp. Bot. 58, 2827-2838. doi: 10.1093/jxb/erm 143

Furch, A. C. U., Zimmermann, M. R., Will, T., Hafke, J. B., and van Bel, A. J. E. (2010). Remote-controlled stop of mass flow by biphasic occlusion in Cucurbita maxima. J. Exp. Bot. 61, 3697-3708. doi: 10.1093/jxb/erq181

Grams, T. E. E., Koziolek, C., Lautner, S., Matyssek, R., and Fromm, J. (2007). Distinct roles of electric and hydraulic signals on the reaction of leaf gas exchange upon re-irrigation in Zea mays L. Plant Cell Environ. 30, 79-84. doi: 10.1111/j.1365-3040.2006.01607.x

Grams, T. E. E., Lautner, S., Felle, H. H., Matyssek, R., and Fromm, J. (2009). Heat-induced electrical signals affect cytoplasmic and apoplastic $\mathrm{pH}$ as well as photosynthesis during propagation through the maize leaf. Plant Cell Environ. 32, 319-326. doi: 10.1111/j.1365-3040.2008.01922.x

Hajirezaei, M. R., Biemelt, S., Peisker, M., Lytovchenko, A., Fernie, A. R., and Sonnewald, U. (2006). The influence of cytosolic phosphorylating glyceraldehyde 3-phosphate dehydrogenase (GAPC) on potato tuber metabolism. J. Exp. Bot. 23, $1-15$

Hedrich, R. (2012). Ion channels in plants. Physiol. Rev. 92, 1777-1811. doi: 10.1152/physrev.00038.2011

Kikuyama, M., and Tazawa, M. (1983). Transient increase of intracellular $\mathrm{Ca}^{2+}$ during excitation of tonoplast-free Chara cells. Protoplasma 117, 62-67. doi: 10.1007/BF01281785

Knoblauch, M., Peters, W. S., Ehlers, K., and van Bel, A. J. E. (2001). Reversible calcium-regulated stopcocks in legume sieve tubes. Plant Cell 13, 1221-1230.

Koehle, H., Jeblick, W, Poten, F. Blaschek, W., and Kauss, H. (1985). Chitosan-elicited callose synthesis in soybean cells 
as a $\mathrm{Ca}^{2+}$-dependent process. Plant Physiol. 77, 544-551. doi: 10.1104/pp.77.3.544

Koziolek, C., Grams, T. E. E., Schreiber, U., Matyssek, R., and Fromm, J. (2004). Transient knockout of photosynthesis mediated by electrical signals. New Phytol. 161, 715-722. doi: 10.1111/j.1469-8137.2004.00985.x

Lautner, S., Grams, T. E. E., Matyssek, R., and Fromm, J. (2005). Characteristics of electrical signals in poplar and responses in photosynthesis. Plant Physiol. 138, 2200-2209. doi: 10.1104/pp.105.064196

Pickard, W. F., Minchin, P. E. H., and Troughton, J. H. (1978). Transient inhibition of translocation in Ipomoea alba L. by small temperature reductions. Aust. J. Plant Physiol. 5, 127-130.

Minchin, P. E. H., and Thorpe, M. R. (1983). A rate of cooling response in phloem translocation. J. Exp. Bot. 34, 529-536. doi: 10.1093/jxb/34.5.529

Spanswick, R. M. (1972). Electrical coupling between the cells of higher plants: a direct demonstration of intercellular transport. Planta 102, 215-227. doi: 10.1007/BF00386892

Spanswick, R. M., and Costerton, J. W. F. (1967). Plasmodesmata in
Nitella translucens: structure and electrical resisitance. J. Cell Sci. 2, 451-464.

Spurr, A. R. (1969). A low-viscosity epoxy resin embedding medium for electron microscopy. J. Ultrastr. Res. 26, 31-43. doi: 10.1016/S00225320(69)90033-1

Stahlberg, R., and Cosgrove, D. J. (1992). Rapid alteration in growth rate and electric potentials upon stem excision in pea seedlings. Planta 187, 523-531. doi: 10.1007/BF00199972

Stahlberg, R., and Cosgrove, D. J. (1994). Comparison of electric and growth responses to excision in cucumber and pea seedlings. I. Short-distance effects are due to wounding. Plant Cell Environ. 18, 33-41. doi: 10.1111/j.13653040.1995.tb00541.x

Stahlberg, R., Cleland, R. E., and Van Volkenburgh, E. (2006). "Slow wave potentials - a propagating electrical signal unique to higher plants," in Communication in Plants - Neuronal Aspects of Plant Life, eds F. Baluska, S. Mancuso, and D. Volkmann (Berlin Heidelberg: Springer Verlag), 291-308.

Stankovic, B., Witters, D. L., Zawadzki, T., and Davies, E. (1998). Action potentials and variation potentials in sunflower: an analysis of their relationship and distinguishing characteristics. Physiol. Plant. 103, 51-58. doi: 10.1034/j.13993054.1998.1030107.x

Stitt, M., Lilley, R. M., Gerhardt, R., and Heldt, H. W. (1989). Metabolite levels in specific cells and subcellular compartments of plant leaves. Methods in enzymology 174, 518-552. doi: 10.1016/0076-6879(89)74035-0

Van Bel, A. J. E., and Ehlers, K. (2005). "Electrical signaling via plasmodesmata," in Plasmodesmata, ed K. J. Oparka (Oxford: Blackwell Publishing), 263-278.

Van Bel, A. J. E., Knoblauch, M. Furch, A. C. U., and Hafke, J. B. (2011). (Questions) ${ }^{n}$ on phloem biology. 1. Electropotential waves, $\mathrm{Ca}^{2+}$ fluxes and cellular cascades along the propagation pathway. Plant Sci. 181, 210-218. doi: 10.1104/pp.107.108241

Volkov, A. G., Adesina, T., Markin, V. S., and Jovanov, E. (2008). Kinetics and mechanism of Dionaea muscipula trap closing. Plant Physiol. 146, 694-702. doi: 10.1007/BF00386844

Williams, S. E., and Pickard, B. G. (1972). Properties of action potentials in Drosera tentacles. Planta 103 193-221. doi: 10.1104/pp.67.4.845

Wright, J. P., and Fisher, D. B. (1981). Measurement of the sieve tube membrane potential. Plant Physiol. 67, 845-848.

Conflict of Interest Statement: The authors declare that the research was conducted in the absence of any commercial or financial relationships that could be construed as a potential conflict of interest.

Received: 14 March 2013; accepted: 16 June 2013; published online: 04 July 2013.

Citation: Fromm J, Hajirezaei M-R, Becker VK and Lautner S (2013) Electrical signaling along the phloem and its physiological responses in the maize leaf. Front. Plant Sci. 4:239. doi 10.3389/fpls.2013.00239

This article was submitted to Frontiers in Plant Physiology, a specialty of Frontiers in Plant Science.

Copyright (C) 2013 Fromm, Hajirezaei, Becker and Lautner. This is an openaccess article distributed under the terms of the Creative Commons Attribution License, which permits use, distribution and reproduction in other forums, provided the original authors and source are credited and subject to any copyright notices concerning any third-party graphics etc. 